One of the Supportline co-ordinators, Gill Gridley, points out that there is "no such thing as a typical call about domestic violence'. She describes the nature of the calls as varied as it depends on the stage at which the woman is at in the relationship. Many women could be said to be 'in denial' about the experience of being a victim and take a long time to admit to themselves, and to others, that they have been abused or assaulted and that their partner or husband is responsible. This can be for a number of reasons; for example, the woman can feel very committed to the relationship and is trying hard to make it work, regardless of the emotional, mental and physical toll that it is taking on her and those around her. The abuse can also become a family secret, so the woman ends up blaming herself.

Excuses for the abusive behaviour are also common; for example, taking the blame for the breakdown of the relationship and the subsequent abuse, and defending the partner's role as a loving parent. However, there is clearly an issue here about the psychological damage suffered by children who are caught up in abusive relationships.

The trained staff and volunteers on the Victim Supportline do not give advice, but they can offer 'emotional support' - a listening ear - and will refer women to other specialist agencies, including Refuge and Women's Aid, if necessary. Gridley says it is essential that victims of domestic violence talk to somebody about their experiences. She stresses that the Supportline does not give advice, such as urging women to leave the relationship. Instead, various options can be suggested and discussed with the caller.

Staff and volunteers in around 300 community-based groups in England, Wales and Northern Ireland (Victim Support Scotland is an autonomous organisation under the Victim Support umbrella) provide emotional support and practical help to victims of crime, witnesses, their families and friends. The service is free and confidential, and the help is provided whether or not the crime has been reported to the police or when it happened.

As Victim Support provides an outreach service, all of the staff and volunteers in the local groups, the criminal courtbased Witness Services and the Victim Supportline receive basic awareness training on the impact of domestic violence. Staff and volunteers who opt to work specifically with victims of domestic violence undergo intensive training.

A number of Victim Support's local groups have gone a step further, as we have seen with the STAR Project, and have set up dedicated services for victims of domestic violence. Trained staff and volunteers will give the woman time to talk about her experiences and feelings and provide information about the options available to her. They can also help with practical issues or liaise with other organisations, including housing authorities.

If the woman decides to report the crime to the police, the local Victim Support group will provide information about the criminal justice system and police procedures. If the case goes to court, the Victim Support-operated Witness Service (based in every criminal court in England and Wales) can provide her with emotional support and information. Witnesses and victims of crime who use the Service can get information about court procedures, pretrial visits and help with filling in forms. Importantly, many also provide separate waiting areas where the woman can sit at a comfortable distance from the perpetrator's family or friends.

Witnesses are supported before, during and after the trial, although for legal reasons the staff and volunteers do not discuss the evidence. However, that does not prevent them from playing a significant part in helping witnesses, victims of crime, their families and friends with coping with the stress of appearing in court. A recent Home Office survey on the Witness Service found that $97 \%$ of those questioned were either 'very satisfied' or 'fairly satisfied' with their experience of the Witness Service. ${ }^{7}$ This positive feedback is very encouraging and clearly shows that the Service's work is effective and widely appreciated. Our staff and volunteers will continue their hard work in the local groups, the Witness Service and on the Victim Supportline to provide a comprehensive service to women who have suffered domestic violence.

Statements on funding and competing interests

Funding. None declared.

Competing interests. The author is Media and PR Officer for Victim Support.

Andrew Buckingham, BA (Hons), PG Dip

Media and PR Officer, Victim Support, Communications Department, Victim Support National Office, Cranmer House, 39 Brixton Road, London SW9 6DZ, UK. Tel: +44 (0) 207896 3750. E-mail: andrew.Buckingham@ victimsupport.org.uk

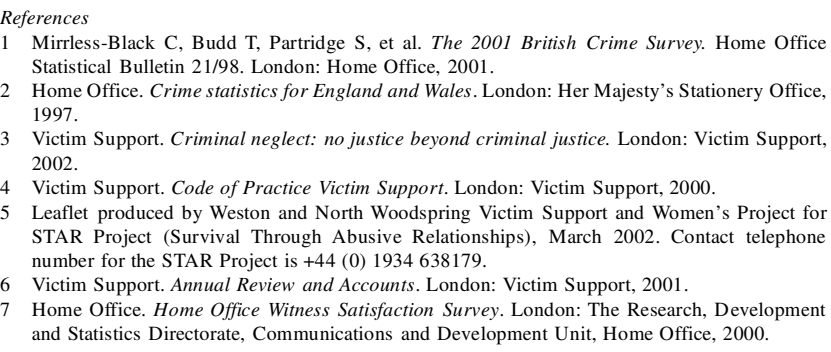

Contact Information. The Supportline can be contacted by callers requiring emotional support on 08453030900 (telephone number for UK callers only). Calls are charged at the local rate, and the line is open on weekdays between $9 \mathrm{am}$ and $9 \mathrm{pm}$, weekends from $9 \mathrm{am}$ to $7 \mathrm{pm}$ and bank holidays between $9 \mathrm{am}$ and $5 \mathrm{pm}$. For general information about the Victim Supportline or to volunteer call +44 (0) 20 7896 3923. Website: www.victimsupport.org

\title{
Sexual abuse and learning disability
}

Sexual abuse of any person is abhorrent whether they are disabled or non-disabled. The emotional and physical repercussions are many for the abused person. Sexual abuse of people with learning disability has been described as 'thinking the unthinkable'. The incidence of reported sexual abuse is high. ${ }^{1}$ This applies only to the known cases: how many other cases remain undetected?
Although the focus is often placed on sexual intercourse (vaginal or anal) there are other aspects of sexual abuse, which has been defined as follows:

- Where sexual acts are performed on or with someone who is unwilling or unable to consent to those acts. ${ }^{2}$

- Any sexual contact which is unwanted and/or unenjoyed by one partner and is for the sexual gratification 
of the other. ${ }^{3}$

- Where that person's apparent willingness is unacceptably exploited. ${ }^{4}$

Choice and consent are essential components of sexual activity; if these are denied then abuse has occurred. In effect, if you feel abused you are abused. Each person with a disability is, of course, an individual and their experience, response and needs will be specific to them. For some abuse will have been in the past, for others in the present and may be ongoing. Generalisations can be unhelpful but some factors need to be considered.

People with learning disabilities are vulnerable. They have often been encouraged 'to be good', 'do as you are told' and 'don't make a fuss', i.e. to be compliant. They frequently like to please others. This, coupled with a wish to be accepted and the inability to have foresight and identify risk, makes them susceptible to exploitation and abuse.

Most people with disabilities spend the majority of their time with other clients so it should not be surprising that the majority of abusive behaviour is carried out by other clients, ${ }^{5}$ abuse by staff, family and strangers being much less prevalent. 6 There is also work to do with the alleged perpetrator.

Due to lack of knowledge and skills, disclosure may be very difficult or even impossible for the abused person. They may not realise that their experience is abuse and that they have the right to complain; nor may they have the words or means to do so. Fear of being chastised or blamed is also a deterrent, in addition to anxiety that they will not be believed. Many of these emotions are shared by nondisabled people in the same situation. Disclosure may depend on observations by other people who, because of the nature of these events, find they cannot or will not believe what they are hearing or seeing. Support, for staff and families, is important in this context.

Disclosure sets in motion a train of events, which necessitates discussion, often with strangers, and may include the police. If events are recent this may include intimate examinations for collection of forensic evidence. Consent and capacity to consent to examinations is crucial in this situation. Everyone, male or female, with or without a disability finds this a difficult experience. Not infrequently people with learning disabilities are worried about using 'rude words' or being rude or naughty when talking about anything relating to sex or examinations of 'private parts'. In recent times there has been greater awareness of difficulties and improvements in working practices when working with vulnerable people. ${ }^{7}$ This is an important step forward.

In addition to clinical measures, such as emergency contraception and investigation and management of sexually transmitted infections (STIs), counselling support needs to be offered. It is necessary to be clear that this is a therapeutic role as sometimes a request is made to gather evidence as part of the counselling process. It is not possible to do both at the same time - any such attempt results in confusion. It is important that evidence is collected before counselling commences to avoid contaminating the evidence.

Many cases do not progress to court, sometimes on account of lack of evidence but also due to the client's difficulty in acting as a reliable witness. Of the 20 abused clients seen personally by the author in the course of a year, in nine cases there was police involvement, three went to court and one abuser was convicted. Clients need support at the time of the event, when a decision is made to progress (or not), at the time of the court appearance, and when the case has concluded.

Health professionals need to be aware of the incidence of sexual abuse. Past abuse may become apparent when carrying out gynaecological examinations including cervical smears. These too are vulnerable times and need sensitive management.

'Prevention is better than cure' - effective safeguards against sexual abuse are the law, knowledge, understanding and self-respect. The last three can be encapsulated in effective sex education and communication. When working with people with learning disabilities it often appears that they have received no sex education. It may be that they were not given any - it may have been deemed unnecessary or irrelevant in the past, or it may have seemed irrelevant to them, perhaps because they had no partner at the time. For others the language or way the information was presented may have been unintelligible. Some clients need 1:1 tuition. Sex education, of course, needs to address issues as well as facts. It may need to start with the difference between men and women or adults and children.

Understanding about personal space, ownership of their body and what is appropriate and inappropriate behaviour is valuable in both keeping safe and avoiding abusive behaviour, i.e. it is useful in reducing the risk of being abused and of being an inadvertent abuser. Allied to this assertiveness skills raise self-esteem and are important in enabling the person to 'keep safe', such that saying 'No' or showing 'No' is effective.

As clinicians we recognise that education is often part of our consultations and that effective communication is essential for the consultation to be valid. Where there is impairment of understanding we have a responsibility to facilitate the consultation. The client is best placed in leading us in their chosen mode of communication whether it be by word, pictures, symbols, signing or computer. They are only too pleased to teach us. By working together towards effective communication and sex education and by making our services more accessible and user-friendly, there is an opportunity to tackle some of the problems of sexual abuse and its consequences for people with learning disabilities.

Statements on funding and competing interests

Funding. None declared.

Competing interests. None declared.

Elaine Cooper, MB ChB, FFFP

Consultant Advisor in Sexuality Issues, West Hampshire NHS Trust, Hawthorn Lodge, Moorgreen Hospital, Botley Road, West End, Southampton SO30 3JB, UK. Tel: +44 (0) 238047 5157. Fax: +44 (0) 2380475160

References

McCarthy M, Thompson D. A prevalence survey of sexual abuse of adults with intellectual disabilities referred for sex education. J Appl Res Intellect Disabil 1997; 10: 105-124.

Brown H, Turk V. Defining sexual abuse as it affects adults with learning disabilities. Ment Handicap 1992, 20: 44-55.

McCarthy M. Sexual experience of women with learning difficulties in long-stay hospitals. Sex McCarthy M. Sexual experie

Matthews H. What staff need to know. It did happen here: sexual abuse and learning disability. Matthews H. What staff need to know. It did happen here: sexual abus

London: St George's Mental Health Library, Conference Series, 1994 .
Thompson D. Profiling abusive behaviour of men with intellectual disabilities. J Appl Res Thompson D. Profiling abusive behaio
Intellect Disabil 1997; 10: 125-139.

Intellect Disabil 1997; 10: 125-139. Stein J, Brown H. Sexual abuse of adults with learning disabilities - the quiz pack. Brighton: Pavilion Publishing, 1996.

Home Office. Achieving best evidence in criminal proceedings - Home Office guidance for vulnerable and intimidated witnesses including children. London: Home Office, Department of Health, 2001.

Further reading

Cooper E, Guillebaud J. Sexuality and disability - a guide for everyday practice. Oxford: Radcliffe Medical Pres, 1999.

Gunn MJ. Sex and the law: a brief guide for staff working with people with learning disabilities. Gunn MJ. Sex and the law: a brief guide for staff
London: Family Planning Association, 1996.

London: Family Planning Association, 1996.
Brown H, Craft A (eds). Thinking the unthinkable - papers on sexual abuse and people with learning difficulties. London: Family Planning Association Education Unit, 1989. 